\section{Saad S Gasgoos}

BDS, MSc (Assist Lect)

Ne'am R Al - Saleem BDS, MSc (Assist Lect)

Khawla M Awni

BDS, MSc (Assist Lect)

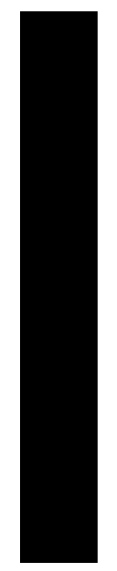

\title{
Cephalometric features of skeletal Class I, II and III (A comparative study)
}

\author{
Dept of Pedod, orthod, and Prev Dentistry
}

College of Dentistry, University of Mosul

\begin{abstract}
Aims: To identify the cephalometric features of three skeletal jaw relations (Class I, II and III). Materials and methods: one hundred thirty four students were selected aged 12-15 years from secondary schools in Mosul City, 45 with Class I normal occlusion as control, 44 with Class II malocclusion and 45 with Class III malocclusion, after taking the lateral cephalometric radiographs according to ANB angle. A 20 variables (12 angular and 8 linear) were used in this study to correlate these variables in the three skeletal Classes. Results: No significant sex differences were observed for the majority of angular and linear measurements for the three skeletal types. Anterior cranial base length (S-N) and saddle angle (NSAr) didn't show significant difference among the three skeletal Classes, the posterior cranial base (S-Ar) was shorter in Class III which indicate the anterior articulation of the mandible. The length of maxillary base (ANS-PNS) was longer in Class II than Class I and III which lead to maxillary prognathism. The body length of the mandible (GoPog),effective mandibular length ( $\mathrm{Ar}-\mathrm{Gn})$ and lower anterior face height was significantly longer in Class III which lead to mandibular prognathism. The SNA angle was significantly smaller in Class III than in the others. SNB and SNPog angles were larger in Class III followed by Class I and then Class II. The gonial angle (Ar-Go- Me) was larger in Class III which acts to increase mandibular effective length. The (N-A-Pog) showed as convex in Class II and concave in Class III. (The U1-PP) angle was larger in Class II followed by Class I and then by Class III. The (L1-MP) angle in Class II and III was significantly smaller than in Class I. Conclusion: Most of the angular and linear measurements indicated that the skeletal differences between the Class I, Class II and Class III are concentrated with in the maxillary and mandibular bases in both the anteroposterior and vertical dimensions and their type of articulation. The dental measurements appear to be compensated with that of skeletal one. Also these variables showed no significant sex differences in the majority of their measurements.

Key words: Angle Class I, Angle Class II, Angle Class III, Cephalometrics.
\end{abstract}

Gasgoos SS, Al-Saleem NR, Awni KM. Cephalometric features of skeletal Class I, II and III (A comparative study). Al-Rafidain Dent J. 2007; 7(2): 122 -130 .

Received: 20/12/2005 Sent to Referees: 21/12/2005 Accepted for Publication: 8/2/2006

\section{INTRODUCTION}

It was found that point of the differences between Class II, Class I and Class III was accounted by systemical variation in a coherent set of midface and cranial base dimensions. These variation were in harmony with each other; the cranial base angle $(\mathrm{Ba}-\mathrm{S}-\mathrm{N})$ closed and the legs $(\mathrm{S}-\mathrm{N})$ and $(\mathrm{S}-\mathrm{Ba})$ shortened systemically from Class II over Class I, to Class III. ${ }^{(1)}$

Cephalometric analysis was comprised both sagittal and vertical measurements for the assess of the position of the glenoid fossa in relation to surrounding skeletal structures. As for sagittal measurements, TMJ position was more posterior in skeletal Class II when compared with skeletal Class III. ${ }^{(2)}$

It is unclear whether malocclusion characterized by jaw discrepancy is caused by variations in mandibular position, mandibular size, or a combination of the two. The mean plots for each of the group were superimposed on S-N and Go-Gn. These showed mandibular form and size to be similar in the Class I and Class III groups and in both divisions of Class II. The position of Class III mandibles was more ant- 
erior and rotate forward in relation to the When used to compare mandibular shape derived from lateral cephalometric between three equal samples of female patients aged (12-15) years, marked overall similarity was noted between patients with Class I, II and III occlusions. ${ }^{(4)}$

Cranial base length correlated strongly with maxillary length but weakly with mandibular length. Nevertheless, the size of the maxilla did not influence its prognathism, the cranial base angle was strongly correlated $(-0.7)$ with angle sella -nasion-point B. So that the cranial base size and shape influence mandibular prognathism by determining the anteroposterior position of the condyle relative to the facial profile. ${ }^{(5)}$

Different head form types establish different lines of craniofacial growth resulting in anatomic subgrouping of Classes I, II and III with characteristic morphologic features. ${ }^{(6)}$

In Class III, more acute cranial base angle may affect the articulation of the condyles resulting in their forward displacement; The reduction in anterior cranial size may affect the position of the maxilla. $^{(7)}$

It was found that the discrepancy of the sagittal jaw relation was mainly caused by protrusive or retrusive position of the mandible relative to the cranial base. ${ }^{(8)}$

Aims of this study were to identify the cephalometric features, the sex difference and the part of craniofacial structures that are responsible in the development of different skeletal Classes.

\section{MATERIALS AND METHODS}

The sample of this study was collected from secondary school in Mosul City, 153 students were selected aged (1215) years, 56 with Class I normal occlusion as control, 51 with Class II malocclusion and 46 with Class III malocclusion. After taking the cephalometric radiographs we exclude some radiographs according to ANB angles, so that:

1. In Class I, ANB angle must be $0-4^{\circ}$.

2. In Class II, ANB angle must be $>4^{\circ}$.

3. In Class III, ANB angle must be $<0^{\circ}$.

After this selection the study was done on 45 Class I, 44 Class II and 45 Class III cephalographs (total 135 ceph- cranial base compared with other groups. ${ }^{(3)}$ alometric radiographs) .

The criteria of sample selection:

1. Full set of permanent dentition excluding third molars.

2. Molar and canine relation:

A. bilateral Class I molar and canine relationship for Class I sample. ${ }^{(9)}$

B. bilateral Class II molar relationship for Class II sample. ${ }^{(9)}$

C. bilateral Class III molar relationship for Class III sample. ${ }^{(9)}$

3. Incisal relation:

A. Normal overbite and overjet $(2-4)$ $\mathrm{mm}$ for Class I sample. ${ }^{(10)}$

Overjet between 0 and $1 \mathrm{~mm}$ was excluded.

B. Class II incisal relationship with overjet more than $5 \mathrm{~mm} .{ }^{(11)}$

Overjet between 4 and $5 \mathrm{~mm}$ was excluded.

C. Class III incisal relationship, edge to edge incisor relation ${ }^{(12)}$, and

negative overjet cases were included in this study. ${ }^{(13,14)}$

4. No functional displacement of the mandible during opening and closing. ${ }^{(15)}$

5. No history of orthodontic treatment or orthognathic surgery. ${ }^{(16)}$

6 . No congenital missing, cleft or other congenital craniofacial problems. ${ }^{(16)}$

7. Good medical history. ${ }^{(17)}$

8. All subjects are Iraqi in origin and live in center of Mosul City.

All radiographs are taken in the $\mathrm{X}$ Ray Department of College of Dentistry, using Cranex Panoramic / Cephalometric imaging system, Soredex, Orion Corporation, Helsinki, Finland. The machine is set at $10 \mathrm{~m} \mathrm{Amp}$ and $77 \mathrm{Kv}$ with $1.0 \mathrm{sec}$. impulse.

Then, the processing was done in the dark room in the X-Ray Department, College of Dentistry at University of Mosul.

The lateral cephalometric radiographs were taken for subject under standardized condition. ${ }^{(18)}$ Each cephalogram was taken in centric occlusion for subject with lips in relaxed position. ${ }^{(19,20)}$

The films were traced on the viewer with the image facing to the right. ${ }^{(21)}$

Twenty measurements were obtained from tracing of lateral cephalometric radiographs, (Fig. 1). 


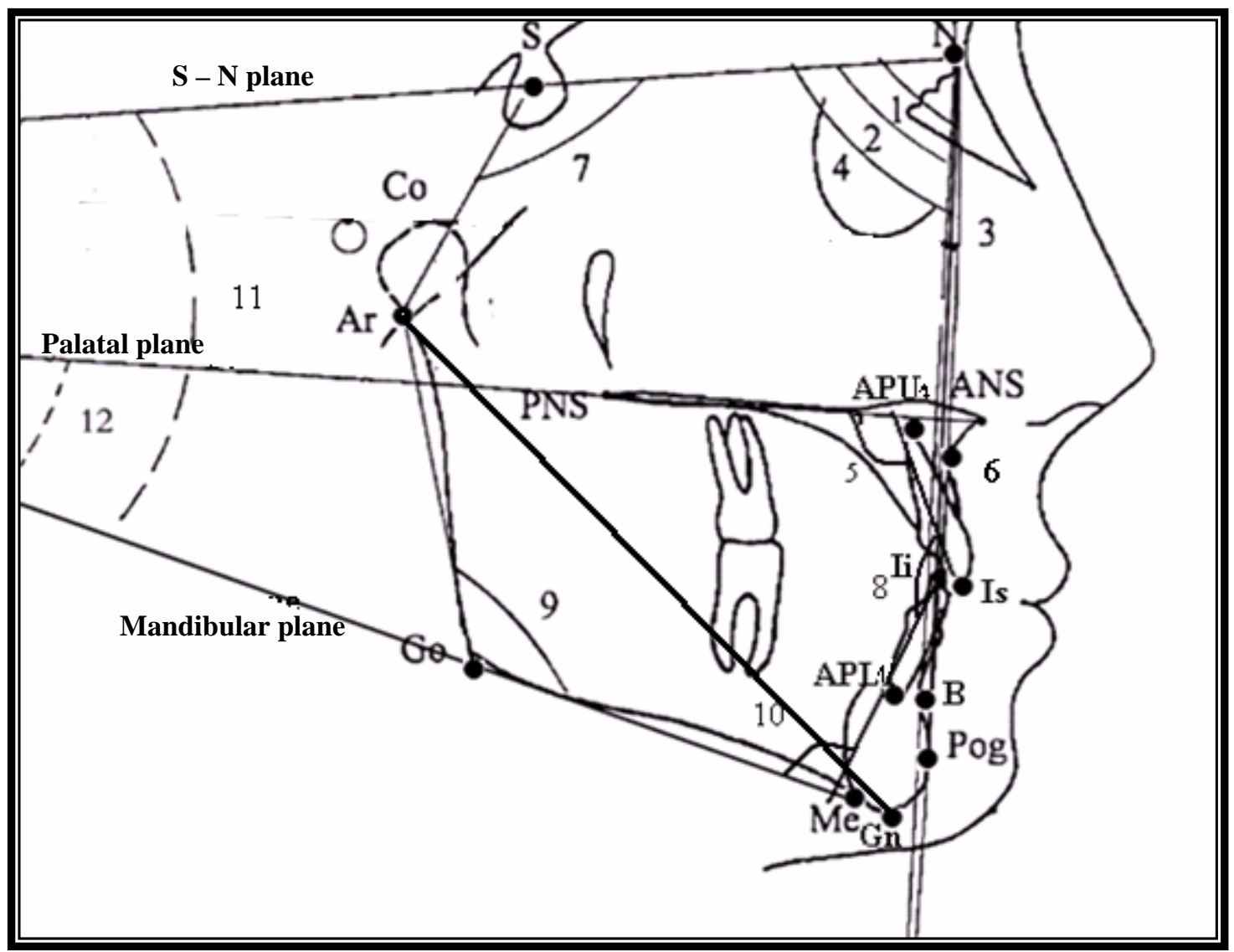

Figure (1): Cephalometric landmarks, planes, linear* and angular** measurements. 1: SNA; 2: SNB; 3: ANB; 4: SNPog; 5: U1/PP; 6: NAPog; 7: NSAr; 8: U1/ L1; 9: ArGoMe; 10: L1/MP; 11: MP-SN; 12: PP-MP; S-N: Anterior cranial base; S - Ar: Posterior cranial base; ANS - PNS: Maxillary base; Ar - Gn: Total mandibular effective length; Go - Pog: Length of the body of the mandible; N - ANS: Upper Anterior Facial Height (UAFH); ANS Me: Lower Anterior Facial Height (LAFH); N - Me: Total Anterior Facial Height (TAFH).

* Length measured in millimeters; ** (1-12) Angle's measured in degrees.

The angular measurements include :

- SNA $^{(22,23)}$

- $\mathrm{SNB}^{(22,23)}$

- $\mathrm{ANB}^{(22-24)}$

- SNPog ${ }^{(24)}$

- Convexity angle (NAPog) ${ }^{(25,26)}$

- Saddle angle (NSAr) ${ }^{(24,26,27)}$

- Gonial angle (ArGoMe) ${ }^{(24,27)}$

- Palatal plane angle (PP / SN) ${ }^{(24)}$

- Mandibular plane angle (MP / SN) ${ }^{(23)}$

- U1 / PP ${ }^{(28-31)}$

- $\mathrm{U} 1 / \mathrm{L} 1^{(23,25)}$

- L1 / MP ${ }^{(25)}$

The linear measurements include:

- S-N: the anterior cranial base length $(24,27,32)$
- S-Ar: the posterior cranial base length $(24,27)$

- ANS- PNS: the maxillary length ${ }^{(33,34)}$

- Ar-Gn: total mandibular effective length

- Go-Pog: the length of the body of the mandible

- Upper Anterior Facial Height (UAFH)

- Lower Anterior Facial Height (LAFH)

- Total Anterior Facial Height (TAFH)

Analysis of the data was done including descriptive statistics (mean and standard deviations) of the variables of different skeletal Classes. ANOVA (Analysis of variance) and Duncan's Multiple Range analysis were performed to identify the groups of variables which were 
responsible for the differences between different skeletal Classes at $P \leq 0.05$.

\section{RESULTS AND DISCUSSION}

No sex differences were seen in the majority of the linear and angular measurements except for SAr distance in Class
I and Class III, LAFH and TAFH distance in Class II, male showed a significantly higher value. While for the angular measurements, U1-PP in Class III was higher in males and SN-MP in Class II was higher in females,(Fig. 2, 3 and 4).

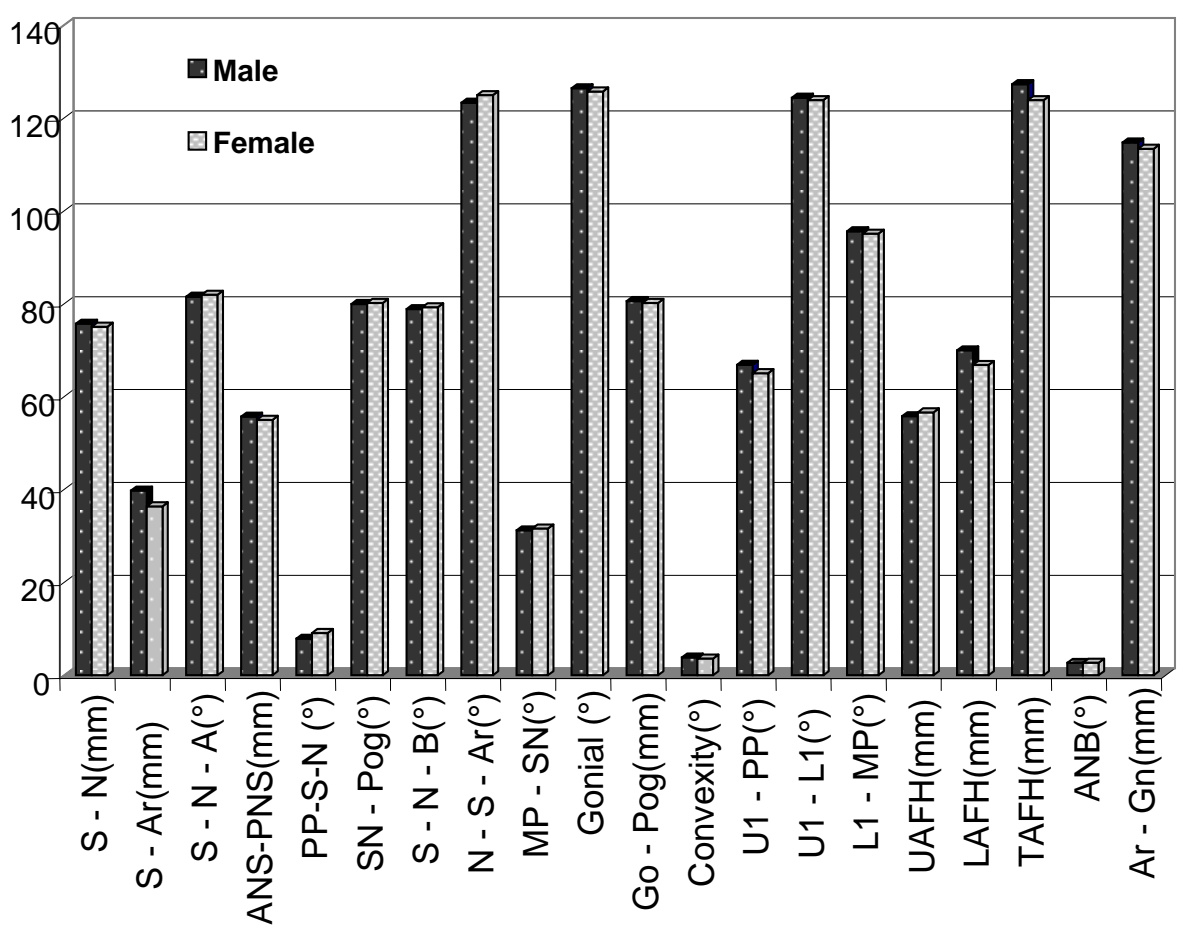

Figure (2): Histogram demonstrates the sex difference of angular and linear measurements in Class I normal occlusion. $(\mathrm{mm})$; length in millimeter. $\left({ }^{\circ}\right)$; Angle in degree.

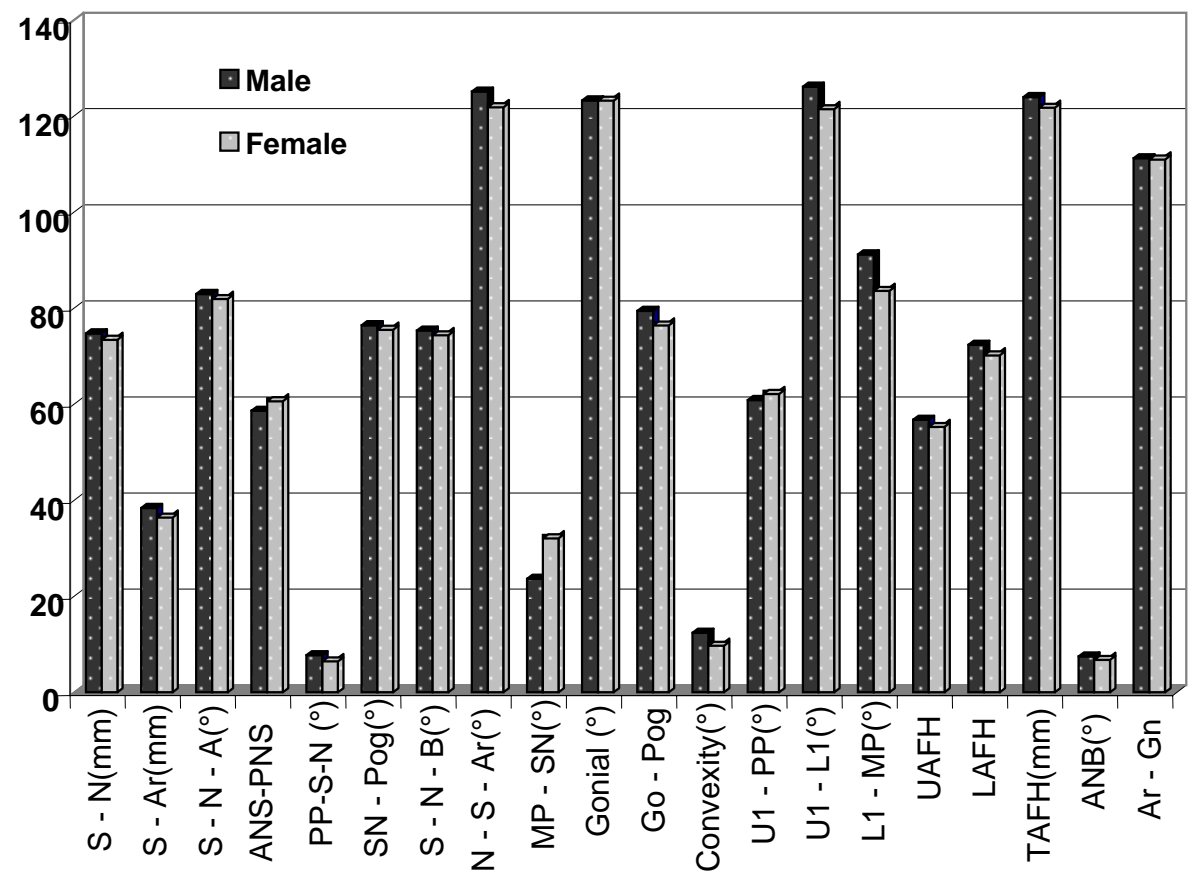

Figure (3): Histogram demonstrates the sex difference of angular and linear measurements in Class II malocclusion. $(\mathrm{mm})$; length in millimeter. $\left({ }^{\circ}\right)$; Angle in degree. 


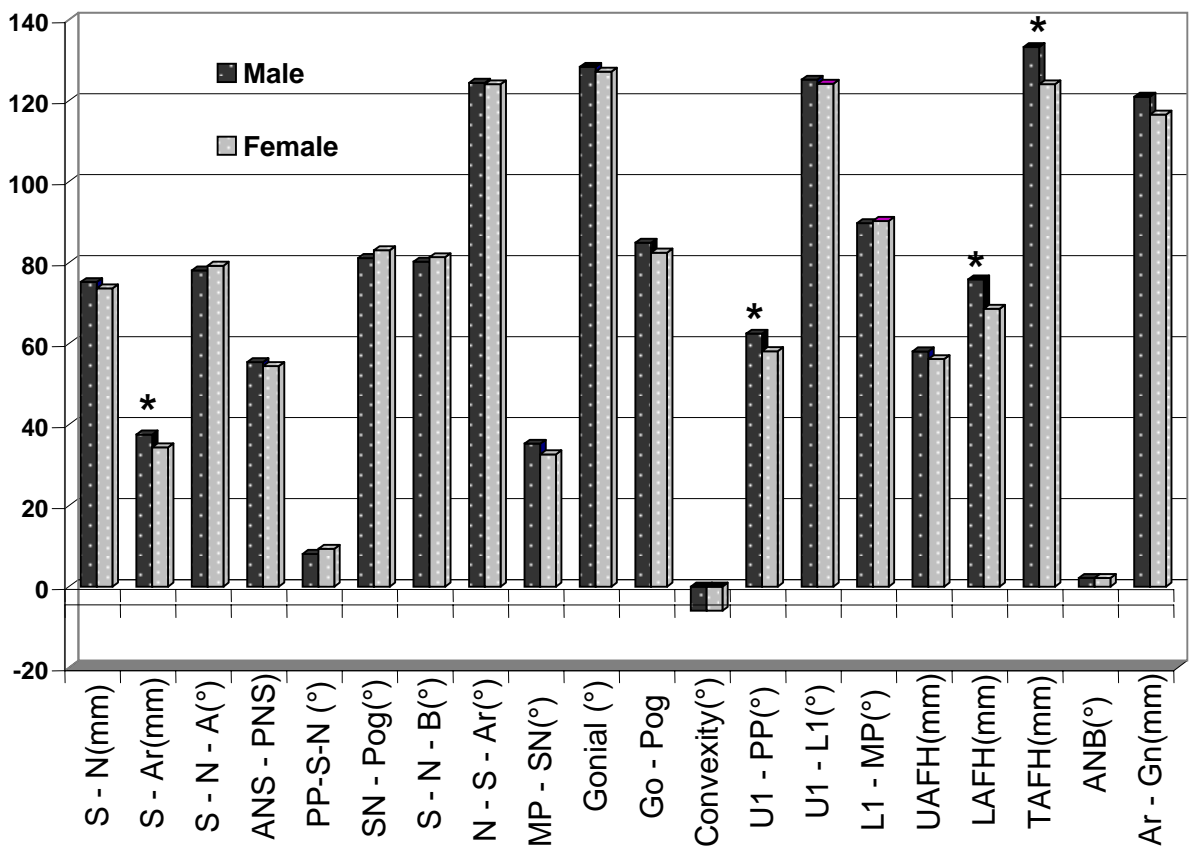

Figure(4): Histogram demonstrates the sex difference of angular and linear measurements in Class III malocclusion. $(\mathrm{mm})$; length in millimeter. $\left(^{\circ}\right)$; Angle in degree.

Angle's Classification of malocclusion is primarily based on skeletal relationships and not so much on occlusion. Significant differences were seen among the three Classes in most of the variables which assume that cephalometric dimensions varied systemically from Class II via Class I to Class III dictating a gradual variation existed in coherent sets of midface and cranial base dimensions, from Class II to Class I and then Class III as shown in Table (1).

Concerning the linear measurements, no significant differences were seen in the anterior cranial base length (SN) among the three Classes, this agreed with the findings of Change et al. ${ }^{(38)}$, but disagreed with that of Dibbets ${ }^{(1)}$, who reported that SN shortened systemically from Class II, over Class I to Class III while others found the reverse. ${ }^{(39)}$ The findings in this research gave the impression that not the length but the configuration of the anterior cranial base would affect on the position of both maxilla and mandible resulting in different Angle's Classes. While the posterior cranial base length (SAr) was shorter in Class III which implicate a forward position of the mandible.

ANS-PNS $\mathrm{mm}$ distance showed a significant higher value in Class II leading into longer maxilla. Bishara et al. ${ }^{(40)}$ mentioned that Class II malocclusion might or might not be associated with long maxilla. Our study ensures that the longer maxillary base length associated with skeletal Class II malocclusion.

On the other hand, the body length of the mandible: Go-Pog and Ar-Gn were significantly longer in Class II cases, so that, when the longer mandible articulate with maxilla give a cephalometric feature of Class III. This agreed with the findings of other researchers who reported a longer mandible in Class III. ${ }^{(38,41)}$

No significant difference was noticed in the UAFH, while LAFH was significantly larger in Class III resulting in a significantly larger $\mathrm{TAFH}$, this can be explained by the forward-downward direction of the growth of the mandible which could be seen in Class III subjects resulting in an increase in the facial height. Said $^{(42)}$, reported a significantly longer UAFH, LAFH and TAFH in Class III subjects. 
Table (1): Duncan's test between the variables of total sample in three skeletal Classes (I, II and III).

\begin{tabular}{|c|c|c|c|c|}
\hline Parameters & Occlusion & Number of sample & Mean \pm SE & Duncan's group* \\
\hline \multirow{3}{*}{$\mathbf{S}-\mathbf{N}(\mathbf{m m})$} & Class I normal occlusion & 45 & $75.395 \pm 0.544$ & $\mathrm{~A}$ \\
\hline & Class II malocclusion & 44 & $74.420 \pm 0.294$ & A \\
\hline & Class III malocclusion & 45 & $74.374 \pm 0.456$ & A \\
\hline \multirow{3}{*}{$S-\operatorname{Ar}(\mathbf{m m})$} & Class I normal occlusion & 45 & $38.026 \pm 0.579$ & $\mathrm{~A}$ \\
\hline & Class II malocclusion & 44 & $37.727 \pm 0.438$ & A \\
\hline & Class III malocclusion & 45 & $35.823 \pm 0.506$ & $\mathrm{~B}$ \\
\hline \multirow{3}{*}{$\mathbf{S}-\mathbf{N}-\mathbf{A}\left(^{\circ}\right)$} & Class I normal occlusion & 45 & $81.734 \pm 0.322$ & $\mathrm{~A}$ \\
\hline & Class II malocclusion & 44 & $82.765 \pm 0.480$ & $\mathrm{~A}$ \\
\hline & Class III malocclusion & 45 & $78.694 \pm 0.446$ & $\mathrm{~B}$ \\
\hline \multirow{3}{*}{ ANS- NS(mm) } & Class I normal occlusion & 45 & $55.340 \pm 0.437$ & $\mathrm{~B}$ \\
\hline & Class II malocclusion & 44 & $59.943 \pm 0.788$ & A \\
\hline & Class III malocclusion & 45 & $54.914 \pm 0.503$ & $\mathrm{~B}$ \\
\hline \multirow{3}{*}{ PP-S-N $\left(^{\circ}\right)$} & Class I normal occlusion & 45 & $8.498 \pm 0.492$ & $\mathrm{~A}$ \\
\hline & Class II malocclusion & 44 & $7.443 \pm 0.511$ & A \\
\hline & Class III malocclusion & 45 & $8.726 \pm 0.519$ & A \\
\hline \multirow{3}{*}{$\mathrm{SN}-\operatorname{Pog}\left({ }^{\circ}\right)$} & Class I normal occlusion & 45 & $80.104 \pm 0.342$ & $\mathrm{~B}$ \\
\hline & Class II malocclusion & 44 & $76.295 \pm 0.469$ & $\mathrm{C}$ \\
\hline & Class III malocclusion & 45 & $82.142 \pm 0.524$ & A \\
\hline \multirow{3}{*}{$\mathbf{S}-\mathbf{N}-\mathbf{B}\left(^{(}\right)$} & Class I normal occlusion & 45 & $79.059 \pm 0.306$ & $\mathrm{~B}$ \\
\hline & Class II malocclusion & 44 & $75.156 \pm 0.482$ & $\mathrm{C}$ \\
\hline & Class III malocclusion & 45 & $80.821 \pm 0.469$ & A \\
\hline \multirow{3}{*}{$\mathbf{N}-\mathbf{S}-\mathbf{A r}\left(^{\circ}\right)$} & Class I normal occlusion & 45 & $124.146 \pm 0.693$ & $\mathrm{~A}$ \\
\hline & Class II malocclusion & 44 & $123.78 \pm 0.775$ & A \\
\hline & Class III malocclusion & 45 & $124.230 \pm 0.767$ & A \\
\hline \multirow{3}{*}{$\mathbf{M P}-\mathbf{S N}\left({ }^{\circ}\right)$} & Class I normal occlusion & 45 & $31.408 \pm 0.615$ & $\mathrm{~A}$ \\
\hline & Class II malocclusion & 44 & $28.204 \pm 1.545$ & $\mathrm{~B}$ \\
\hline & Class III malocclusion & 45 & $33.876 \pm 0.847$ & $\mathrm{~A}$ \\
\hline \multirow{3}{*}{ Gonial $\left(^{\circ}\right)$} & Class I normal occlusion & 45 & $126.056 \pm 0.644$ & $\mathrm{~B}$ \\
\hline & Class II malocclusion & 44 & $123.526 \pm 0.462$ & A \\
\hline & Class III malocclusion & 45 & $127.761 \pm 1.008$ & $\mathrm{~B}$ \\
\hline \multirow{3}{*}{ Go - Pog (mm) } & Class I normal occlusion & 45 & $80.371 \pm 0.572$ & $\mathrm{~B}$ \\
\hline & Class II malocclusion & 44 & $78.227 \pm 0.981$ & $\mathrm{~B}$ \\
\hline & Class III malocclusion & 45 & $83.611 \pm 0.742$ & $\mathrm{~A}$ \\
\hline \multirow{3}{*}{ Convexity $\left(^{\circ}\right)$} & Class I normal occlusion & 45 & $3.713 \pm 0.520$ & $\mathrm{~B}$ \\
\hline & Class II malocclusion & 44 & $11.409 \pm 0.626$ & $\mathrm{~A}$ \\
\hline & Class III malocclusion & 45 & $-6.363 \pm 0.542$ & $\mathrm{C}$ \\
\hline \multirow{3}{*}{$\mathbf{U 1}-\mathbf{P P}\left(^{\circ}\right)$} & Class I normal occlusion & 45 & $65.940 \pm 0.896$ & $\mathrm{~B}$ \\
\hline & Class II malocclusion & 44 & $61.830 \pm 1.158$ & A \\
\hline & Class III malocclusion & 45 & $60.126 \pm 0.963$ & $\mathrm{C}$ \\
\hline \multirow{3}{*}{$\mathbf{U} 1-\mathbf{L} 1\left(^{\circ}\right)$} & Class I normal occlusion & 45 & $124.128 \pm 0.941$ & $\mathrm{~A}$ \\
\hline & Class II malocclusion & 44 & $124.612 \pm 1.156$ & A \\
\hline & Class III malocclusion & 45 & $124.638 \pm 0.933$ & $\mathrm{~A}$ \\
\hline \multirow{3}{*}{$\mathbf{L 1}-\mathbf{M P}\left({ }^{\circ}\right)$} & Class I normal occlusion & 45 & $95.351 \pm 0.897$ & $\mathrm{~A}$ \\
\hline & Class II malocclusion & 44 & $90.042 \pm 2.697$ & $\mathrm{~B}$ \\
\hline & Class III malocclusion & 45 & $87.713 \pm 0.790$ & $\mathrm{~B}$ \\
\hline \multirow{3}{*}{ UAFH (mm) } & Class I normal occlusion & 45 & $56.226 \pm 0.460$ & $\mathrm{~A}$ \\
\hline & Class II malocclusion & 44 & $56.363 \pm 0.420$ & A \\
\hline & Class III malocclusion & 45 & $57.060 \pm 0.507$ & A \\
\hline & Class I normal occlusion & 45 & $68.357 \pm 0.858$ & $\mathrm{~B}$ \\
\hline LAFH (mm) & Class II malocclusion & 44 & $71.602 \pm 0.995$ & A \\
\hline & Class III malocclusion & 45 & $71.970 \pm 0.988$ & A \\
\hline & Class I normal occlusion & 45 & $125.579 \pm 1.000$ & $\mathrm{~B}$ \\
\hline TAFH (mm) & Class II malocclusion & 44 & $123.120 \pm 1.382$ & $\mathrm{C}$ \\
\hline & Class III malocclusion & 45 & $128.343 \pm 1.313$ & A \\
\hline & Class I normal occlusion & 45 & $2.675 \pm 0.127$ & $\mathrm{~A}$ \\
\hline ANB $\left(^{\circ}\right)$ & Class II malocclusion & 44 & $7.463 \pm 0.226$ & $\mathrm{~B}$ \\
\hline & Class III malocclusion & 45 & $-2.126 \pm 0.232$ & $\mathrm{C}$ \\
\hline & Class I normal occlusion & 45 & $114.080 \pm 0.561$ & $\mathrm{~A}$ \\
\hline $\mathrm{Ar}-\mathrm{Gn}(\mathbf{m m})$ & Class II malocclusion & 44 & $111.060 \pm 0.542$ & B \\
\hline & Class III malocclusion & 45 & $118.76 \pm 0.628$ & $\mathrm{C}$ \\
\hline
\end{tabular}

\footnotetext{
* Different letters vertically mean significant difference at $p \leq 0.05$.
} 
Concerning the angular measurements: No significant differences where seen between Class I and Class II in SNA angle, while Class III demonstrated a significantly smaller value producing more retruded position of the maxilla which play a major role in the development of Class III. While SNB and SNPog angles demonstrated a significant difference among the three Classes with the highest value in Class III followed by Class I and then Class II. These findings might focus the light on the retrusion of the mandible as the most important cause of Class II malocclusion, while Class III might be due to retrusion of the maxilla, protrusion of the mandible or combination of both. This comes in agreement with the authors. ${ }^{(30,31,43,44)}$

The saddle angle (NSAr) showed no significant difference among the three Classes which not play a major rule in the skeletal relationship between maxilla and mandible. Although some studies found the saddle angle to be smaller in Class III and larger in Class II like Bacon et al. ${ }^{(45)}$, others found it similar in three Classes, Well. $^{(46)}$

The Gonial angle (Ar-Go-Me) was significantly higher in Class III which result from the increase in the effective length of the mandible causing an increase in the angle.

An obvious significant difference in the facial convexity among the three Classes with the convex profile for Class II to a straight one in Class I reaching to a concave profile in Class III. The position of the maxilla and mandible in relation to nasion $(\mathrm{N})$ in the three Classes with the advancement of maxilla or retrusion of the mandible in Class II, retrusion of the maxilla, protrusion of the mandible in Class III and the normal position of both in Class I could be responsible for this variation in facial convexity among the three Classes.

MP-SN angle was significantly smaller in Class II leading into a steeper mandibular plane angle in Class II compared with Class I and Class III, this can be attributed to the direction of growth of the mandible in Class II.

For the dental angular measurements: No significant differences were seen in the interincisal angle (U1-L1) among the three Classes. In spite of the different positions of the jaws and dental arches in the three Classes. The compensatory growth between the upper and lower dental arches can explain this finding.

Dento-alveolar compensation for apical dysplasia can explain the differrences seen in the angulations of the upper incisor in relation to palatal plane (U1-PP) with the highest value for Class II followed by Class I and then Class III, and the differences seen in the lower incisor inclination in relation to the mandibular plane (L1MP), where Class II and Class III showed significantly smaller value than Class I.

\section{CONCLUSION}

No sex differences were seen in the majority of the linear and angular measurements except for SAr distance in Class I and Class III, LAFH and TAFH distance in Class II which were significantly higher in males and for angular measurements: U1-PP in Class III was higher in males, SN-MP in Class II was higher in females.

Significant differences were seen in most of the linear measurements some of them were higher in Class II: SAr, ANSPNS, others in Class III: Go-Pog, TAFH, LAFH; While SN and UAFH demonstrated no significant difference among the three Classes.

Concerning the skeletal angular measurements, various degrees of significant were seen among the three Classes in different measurements: SNA, angle of facial convexity were higher in Class III, while: MP-SN, SNB, SNPog, Gonial angles were higher in Class III. Saddle angle showed no significant differences in the three Classes.

For dental angular measurements: No significant difference was seen in U1-L1 among the three Classes. U1-PP was significantly higher in Class II, while L1MP was significantly higher in Class I.

\section{REFERENCES}

1. Dibbets JM. Morphological associations between the Angle's Classes. Eur J Orthod. 1996; 18(2): 111-118.

2. Baccetti T, Antonini A, Franchi L, Tonti M, Tollaro I. Glenoid fossa position in 
different facial types: a cephalometric study. Br J Orthod. 1997; 24(1): 55 - 59.

3. Kerr WJ, Miller S, Ayme B, Wilhelm N. Mandibular form and position in 10-years-boys. Am $J$ Orthod Dentofacial Orth-op. 1994; 106(2): 115-120.

4. Lavelle CL. A study of mandibular shape. Br J Orthod. 1984; 11(2): 69 - 74.

5. Kerr WJ, Adams CP. Cranial base and jaw relationship. Am J Phys Anthropol. 1988; 77 (2): $213-220$.

6. Martone VD, Enlow DH, Hans MG, Broadbent BH Jr, Oyen O. Class I and Class III malocclusion subgroupings related to headform type. Angle Orthod. 1992; 62(1): $35-42$.

7. Singh GD. Morphologic determinants in the etiology of Class III malocclusions: a review. Clin Anat. 1999; 12(5): 382 405.

8. Arat M, Iseri H, Ozdiler E. Evaluation of skeletal structures in individuals with malocclusion. Ankara Univ Hekim Fak Derq. 1989; 16(1): 29 - 34.

9. Angle EH. Treatment of Malocclusion of Teeth. $7^{\text {th }}$ ed. Philadelphia, S.S. White Manufacturing Co. 1907; Pp: 40 -52.

10. Kinaan BK. Overjet and overbite distribution and correlation. A comparative epidemiological English Ira-qi Study. $\mathrm{Br}$ J Orthod. 1986; 12: $79-86$.

11. Hayness S. The distribution of overjet and overbite in English children aged 11-12 years. Dental Practitioner. 1972; 34: $380-383$.

12. Houston WJB. Walthers Orthodontic Notes. $4^{\text {th }}$ ed. Bristol, John Wiley and Sons Ltd. 1983; Pp: 1, 154.

13. Foster TD. A textbook of Orthodontics. $2^{\text {nd }}$ ed. Blackwell Scientific Publications. 1982; Pp: 25 - 41, 313.

14. Ngan P, Hu AM, Field HW. Treatment of Class III problems begins with differrential diagnosis of anterior cross bites. Pediatr Dent. 1997; 19(6): 386 - 395.

15. Dietrich VC. Morthological variability of skeletal Class III relationships as revealed by cephalometric ana-lysis. Trans Eur Orthod Soc. 1970; 46: 131- 143.

16. Mouakeh M. Cephalometric evaluation of craniofacial pattern of Syrian children with Class III malocclusion. Am J Orthod Dentofacial Orthop. 2001; 119: 640 -649 .

17. Ursi BW, Trotman CA, McNamara JA,
Behrent RG. Sexual dimorphism in normal craniofacial growth. Angle Orthod. 1993; 63(1): $47-56$.

18. Major WP, Johnson DE, Hesse KL, Glover KE. Effect of head orienttation on posterior anterior cephalometric landmark identification. Angle Orthod. 1996; 66(1): $51-60$.

19. Hillesund E, Field D, Zachrisson BU. Reliability of soft tissue profile in cepha-lometrics. Am J Orthod. 1978; 74: $537-550$.

20. Lundestrom T, Forsbery CM, Peak S, McWilliam J. A proportional analysis of the soft tissue facial pro-file on young adult with normal occlusion. Angle Orthod. 1992; 62: 127 - 133.

21. Jacobson A, Caufield P. Introduction to Radiographic Cephalometry. Lea and Febiger, Philadelphia. 1985.

22. Riedel RA. Relation of Maxillary structures to cranium in malocclusion and in normal occlusion. Angle Orthod. 1952; 22: $142-145$.

23. Steiner CC. Cephalometrics for you and me. Am J Orthod. 1953; 39: 729 - 755.

24. Rakosi T. An atlas and Manual of Cephalometric Radiography. Wolfe Medical Publication Ltd. $2^{\text {nd }}$ ed Great Britain 1982; Pp: $37-71$.

25. Downs WB. Variation in facial relationnships, their significance in treatment and prognosis. Am J Orthod. 1948; 38: $812-840$.

26. Klocke A, Nanda RM, Kahl - Nieke B. Role of cranial base flexure in the developing sagittal jaws discrepancies. Am J Orthod Dentofacial Orthop. 2002; 122: $386-391$.

27. Bjrk A. The face in profile: an anthropological X-ray investigation on Swedish children and conscripts. Svensk Tandlakare. 1947; 40(5): $164-180$.

28. Rakosi T. The significance of reon-tgenographic cephalometric in the diagnosis and treatment of Class III malocclusions. Trans Eur Orthod Soc. 1970; 43: 155-170.

29. Maj G, Luzi C, Lucchese P. A cephalometric appraisal of Class II and Class III malocclusion. Angle Orthod. 1960; 30(1): $27-34$.

30. Guyer EC, Ellis E, Mcnamara JA, Behrents RG. Components of Class III malocclusion in juvenile and adolescent. 
Angle Orthod. 1986; 56(1): 7 - 31.

31. Hashin HA and Sarhan OA. Dento - skeletal components of Class III malocclusion for children with normal and protruded mandibles. $J$ Clin Pediatric Dent. 1993; 18(1): 12 - 16.

32. Broadbent BH. The face of normal child. Angle Orthod. 1937; 7(4): 183 - 208.

33. Ingerslev $\mathrm{CH}$, Solow B. Sex differences in craniofacial morphology. Acta Odont Scand. 1974; 9: 85 - 93.

34. Tom AP. Class III malocclusion: a cephalometric study of Saudi Arabians. $\mathrm{Br} J$ Orthod. 1989; 16: 201 - 206.

35. McNamara JAJr. A method of cephalometric evaluation. Am J Orthod Dentofacial Orthop. 1984; 86(6): 449 - 469.

36. Sperry TP. An Evaluation of the relation between rest position of the mandible and malocclusion. Angle Orthod. 1989; 59(3): 217 - 226.

37. Biggerstaff RH, Allen RC, Tuncay OC, Berkowitz J. A vertical cephalometric analysis of the human craniofacial complex. Am J Orthod. 1977; 72(4): 397 405.

38. Chang HP, Kinoshita Z, Zawamoto T. Craniofacial pattern in Class III deciduous dentition. Angle Orthod. 1992; 62: $139-144$.

39. Obaidi HA, The variation of the cranial base parameters in Class I, II and III skeletal relationships. Al-Rafidain Dent $J$ 2007; 7(1): 6-13.

40. Bishara S, Jakobsen J, Vorhies B, Bayati P. Change in dentofacial structures in untreated Class II div-ision 1 and normal subjects: a longitudinal study. Angle Orthod. 1997; 1: $55-66$.

41. Battagel MJ. The etiological factors in Class III malocclusion. Eur J Orthod. 1993; 15: $347-370$.

42. Said R. The differential diagnosis of Angle Class III malocclusion in adolescents in Mosul City. MSc thesis. College of Dentistry. University of Mosul. 2004.

43. Al-Ghannaq M. Dentoskeletal patterns in Class II division 1: A cross sectional growth study. MSc. thesis, College of Dentistry. University of Baghdad. 1993.

44. Rosenblum R. Class II malocclusion: mandibular retrusion or maxillary protrusion. Angle Orthod. 1995; 65: 49 - 62.

45. Bacon W, Eiller V, Hildwein M, Dobois $\mathrm{G}$. The cranial base in subjects with dental and skeletal Class II. Eur J Orthod. 1992; 14: $224-228$.

46. Wells D. A, multivariate cephalometric study of Class II division 2 malocclusion. MSc. Thesis. University of Michigan. 1970. 